\title{
Regulation of membrane excitability: a convergence on voltage-gated sodium conductance
}

\author{
Wei-Hsiang Lin • Richard A. Baines
}

Received: 17 January 2014 / Accepted: 11 March 2014 / Published online: 29 March 2014

(C) The Author(s) 2014. This article is published with open access at Springerlink.com

\begin{abstract}
The voltage-gated sodium channel $\left(\mathrm{Na}_{\mathrm{v}}\right)$ plays a key role in regulation of neuronal excitability. Aberrant regulation of $\mathrm{Na}_{\mathrm{v}}$ expression and/or function can result in an imbalance in neuronal activity which can progress to epilepsy. Regulation of $\mathrm{Na}_{\mathrm{v}}$ activity is achieved by coordination of a multitude of mechanisms including RNA alternative splicing and translational repression. Understanding of these regulatory mechanisms is complicated by extensive genetic redundancy: the mammalian genome encodes ten $\mathrm{Na}_{\mathrm{v}} \mathrm{s}$. By contrast, the genome of the fruitfly, Drosophila melanogaster, contains just one $\mathrm{Na}_{\mathrm{v}}$ homologue, encoded by paralytic $\left(D m N a_{v}\right)$. Analysis of splicing in $D m N a_{v}$ shows variants exhibit distinct gating properties including varying magnitudes of persistent sodium current $\left(\mathrm{I}_{\mathrm{NaP}}\right)$. Splicing by Pasilla, an identified RNA splicing factor, alters $\mathrm{I}_{\mathrm{NaP}}$ magnitude as part of an activity-dependent mechanism. Enhanced $\mathrm{I}_{\mathrm{NaP}}$ promotes membrane hyperexcitability that is associated with seizure-like behaviour in Drosophila. Nova-2, a mammalian Pasilla homologue, has also been linked to splicing of $\mathrm{Na}_{\mathrm{v}} \mathrm{s}$ and, moreover, mouse gene knockouts display seizure-like behaviour.

Expression level of $\mathrm{Na}_{\mathrm{v}} \mathrm{S}$ is also regulated through a mechanism of translational repression in both flies and mammals. The translational repressor Pumilio (Pum) can bind to $N a_{v}$ transcripts and repress the normal process of translation, thus regulating sodium current $\left(\mathrm{I}_{\mathrm{Na}}\right)$ density in neurons. Pum2deficient mice exhibit spontaneous EEG abnormalities. Taken together, aberrant regulation of $\mathrm{Na}_{\mathrm{v}}$ function and/or expression is often epileptogenic. As such, a better understanding of regulation of membrane excitability through RNA alternative splicing and translational repression of $\mathrm{Na}_{\mathrm{v}} \mathrm{s}$ should provide new leads to treat epilepsy.
\end{abstract}

W.-H. Lin $\cdot$ R. A. Baines $(\bowtie)$

Faculty of Life Sciences, University of Manchester, Oxford Road, Manchester, UK

e-mail: Richard.Baines@manchester.ac.uk
Keywords Excitability $\cdot$ Drosophila $\cdot$ Epilepsy $\cdot$ Paralytic . Splicing $\cdot$ Translational repression

\section{Introduction}

The regulation of neuronal excitability—primarily the ability to maintain action potential firing within physiological constraints - is an important mechanism for maintenance of neuronal stability [1]. Without such regulation, chronic changes in levels of synaptic excitation have the potential to destabilise neural circuits leading to an imbalance in neuronal activity. One consequence of activity imbalance is seizure, which if recurrent is termed epilepsy [2]. The voltage-gated sodium channel $\left(\mathrm{Na}_{\mathrm{v}}\right)$ plays a key role in the regulation of neuronal excitability because its activation results in action potential firing. It is perhaps, therefore, not surprising that many mechanisms that act to stabilise neuronal activity do so through modifying the activity of this class of ion channel [1, 3-7].

Ten genes (SCN1A-SCN11A), encoding pore-forming $\alpha$ subunits, are present in mammals [8]. This relatively high number is, however, insufficient to support the wide diversity of $\mathrm{Na}_{\mathrm{v}}$ kinetics reported in the nervous system. Diversity of signalling is critically reliant on additional mechanisms such as alternative splicing, RNA editing, and protein modification (i.e., phosphorylation) [9-12, 4]. However, whilst the importance of posttranscriptional and posttranslational modifications is appreciated for refining activity of channel subtypes, understanding of the mechanisms that neurons employ to determine which form of $\mathrm{Na}_{\mathrm{v}}$ to express remains rudimentary. In contrast to mammals, the genome of the fruitfly Drosophila melanogaster contains only one $\mathrm{Na}_{\mathrm{v}}$ channel homologue: encoded by paralytic $\left(D m N a_{v}\right)[13,5]$. The lack of redundancy, coupled with a high degree of structural and functional homology, makes $\mathrm{DmNa}_{\mathrm{v}}$ an advantageous model with which to study the role of this ion channel family [14, 
15]. In this review, we use $\mathrm{DmNa}_{\mathrm{v}}$ as a model to summarise recent findings relating to how neurons generate diversity in $\mathrm{Na}_{\mathrm{v}}$ channel activity and to stabilise neuronal circuit function when faced with changing levels of synaptic excitation.

Alternative splicing generates diversity in $\mathrm{Na}_{\mathrm{v}}$ channel activity

Alternative splicing involves the substitution, removal, and/or inclusion of exonic sequences within a pre-messenger RNA (mRNA) to produce transcripts encoding related protein isoforms [9]. Estimates indicate that $\sim 95 \%$ of human genes are alternatively spliced $[16,17]$. Variant transcripts of $D m N a_{v}$, first reported by Loughney et al., (1989), were among the first evidence for the existence of alternative splicing of this family of gene products. Subsequent studies in Drosophila, Musca, and cockroach have identified 15 alternatively spliced exons $[18,19,14,20,15]$. Importantly, alternative splicing of exons is replicated in mammalian $\mathrm{Na}_{\mathrm{v}}$ channels [21-23]. Spliced exons are conserved across evolutionarily diverged species, strongly indicative of fundamental physiological importance.

A recent structure-function study has described the effects to $\mathrm{DmNa}_{\mathrm{v}}$ channel kinetics of alternative splicing [15]. Of the 15 known splice decisions, two splice events are mutually exclusive incorporating one of either a pair of exons $(C / D$ and $K / L)$. Both exon pairs are membrane spanning, contributing to domains IIS4-5 and IIIS3-4, respectively. The remaining 11 spliced exons $(J, 7,8, I, A, B, E, F, 22, H, 23)$ are independent and cytoplasmic. Heterologous expression of $D m N a_{v}$ splice variants in Xenopus oocytes shows that such splicing imparts specific attributes to channel kinetics. For example, inclusion of exon $F$ results in a hyperpolarising shift in activation kinetics, indicative of increased excitability for those neurons that express $F$-containing variants. By contrast, inclusion of exons $J$ and $E$ results in a depolarising shift of activation voltages which are predicted to reduce neuron excitability. On the other hand, channels expressing exon $H$ inactivate at more depolarised voltages, predicted to make neurons more excitable. Finally, the choice to include mutually exclusive exons $K$ or $L$ markedly affects the magnitude of the persistent current $\left(\mathrm{I}_{\mathrm{NaP}}\right)$ that arises from incomplete inactivation of the channel [24, 5, 25]. Inclusion of exon $K$ results in a smaller $\mathrm{I}_{\mathrm{NaP}}$ relative to that observed from expression of transcripts that contain exon $L$, in otherwise identical channels. Increasing $\mathrm{I}_{\mathrm{NaP}}$ leads to an increased frequency of action potential firing $[26,5]$. Figure 1 summarises the known splicing events of $D m N a_{v}$, and the effect on channel kinetics and/or $\mathrm{I}_{\mathrm{NaP}}$ is summarised in Table 1. Of course, the caveat to heterologous expression is that the nature of the cell membrane of the cell type used may influence the kinetics of expressed channels compared to expression, in this instance, in Drosophila neurons [27]. Attempts to express $D m N a_{v}$ variants in Drosophila neurons, using the well-characterised GAL4/UAS system, has repeatedly failed to produce functional channels, for unknown reasons (Lin and Baines, unpublished observations).

Both embryonic and adult Drosophila CNS expresses a wide diversity of $D m N a_{v}$ splice forms. However, the profile of splicing differs between these two stages. This is indicative that different $\mathrm{Na}_{\mathrm{v}}$ properties are required at each stage and that these differences are achieved through splicing. Differences of spliced exons expressed in these two stages include a greater usage of exon $J(89 \%)$ but not of exon $F(10 \%)$ in adults and vice versa in embryos $(10 \%$ exon $J$ and $78 \%$ exon $F)$ [14, 15]. However, the physiological significance of these differences is not clear. It is interesting to note that $D m N a_{v}$ transcripts which lack a majority of common cytoplasmically located spliced exons result in channels with shifted activation and inactivation kinetics towards hyperpolarised and depolarised voltages, respectively, and which also exhibit a much larger $\mathrm{I}_{\mathrm{NaP}}$. These properties are predicted to make neurons highly excitable [15]. Similarly, analysis of splicing of $N a_{v}$ in other insects shows that it is important for functional properties of the expressed channel. For example, exclusion of optional exon $B$ (located at the linker between the domains I and II, but not equivalent to exon $B$ in Drosophila) in cockroach sodium channels $\left(B g N a_{v}\right)$ potentiates the amplitude of the fast-activating and inactivating $\mathrm{I}_{\mathrm{Na}}$ transient current $\left(\mathrm{I}_{\mathrm{NaT}}\right)$, which is likely to increase cell excitability (Table 1) [28]. Indeed, an emerging theme is that splicing in of optional exons primarily reduces channel activity and hence, membrane excitability, in order to suit the requirements of neural signalling.

Splicing in intracellular coding regions of mammalian $\mathrm{Na}_{\mathrm{v}} \mathrm{S}$ can also result in changes to channel activity. For example, the human $N a_{v} 1.3(S C N 3 A)$ alternative spliced exon 12, which encodes an intracellular loop between domains I and II, results in the generation of multiple isoforms. By using multiple splice donor sites in exon 12, four different variants are produced: $12 \mathrm{v} 1,12 \mathrm{v} 2,12 \mathrm{v} 3$, and $12 \mathrm{v} 4$. The variant $12 \mathrm{v} 4$, when compared to $12 \mathrm{v} 2$, seemingly increases membrane excitability by shifting activation kinetics of the expressed $\mathrm{I}_{\mathrm{Na}}$. By contrast, inactivation kinetics showed a shift toward hyperpolarising potentials for $12 \mathrm{v} 1$ over $12 \mathrm{v} 3$, indicative that expressing $12 \mathrm{v} 1$ might be expected to decrease membrane excitability (Table 1) $[29,30]$. Taken together, $\mathrm{Na}_{\mathrm{v}}$ gating properties can be determined by the inclusion of exons to alter membrane excitability. However, details of how inclusion of specific spliced exons change gating of the affected channels remains to be determined. A possible mechanism for altering channel kinetics is the phosphorylation state of the channel $[30,31]$. Analysis of the amino acid sequence of human $\mathrm{Na}_{\mathrm{v}} 1.3$ splice variants revealed the presence of two additional phosphorylation sites (protein kinase $\mathrm{C}$ on $\mathrm{Ser}^{631 / 632}$ and casein kinase II on $\mathrm{Ser}^{646}$ ) in $12 \mathrm{v} 3$ and $12 \mathrm{v} 4$ that are absent from other variants [30]. Changing membrane excitability 


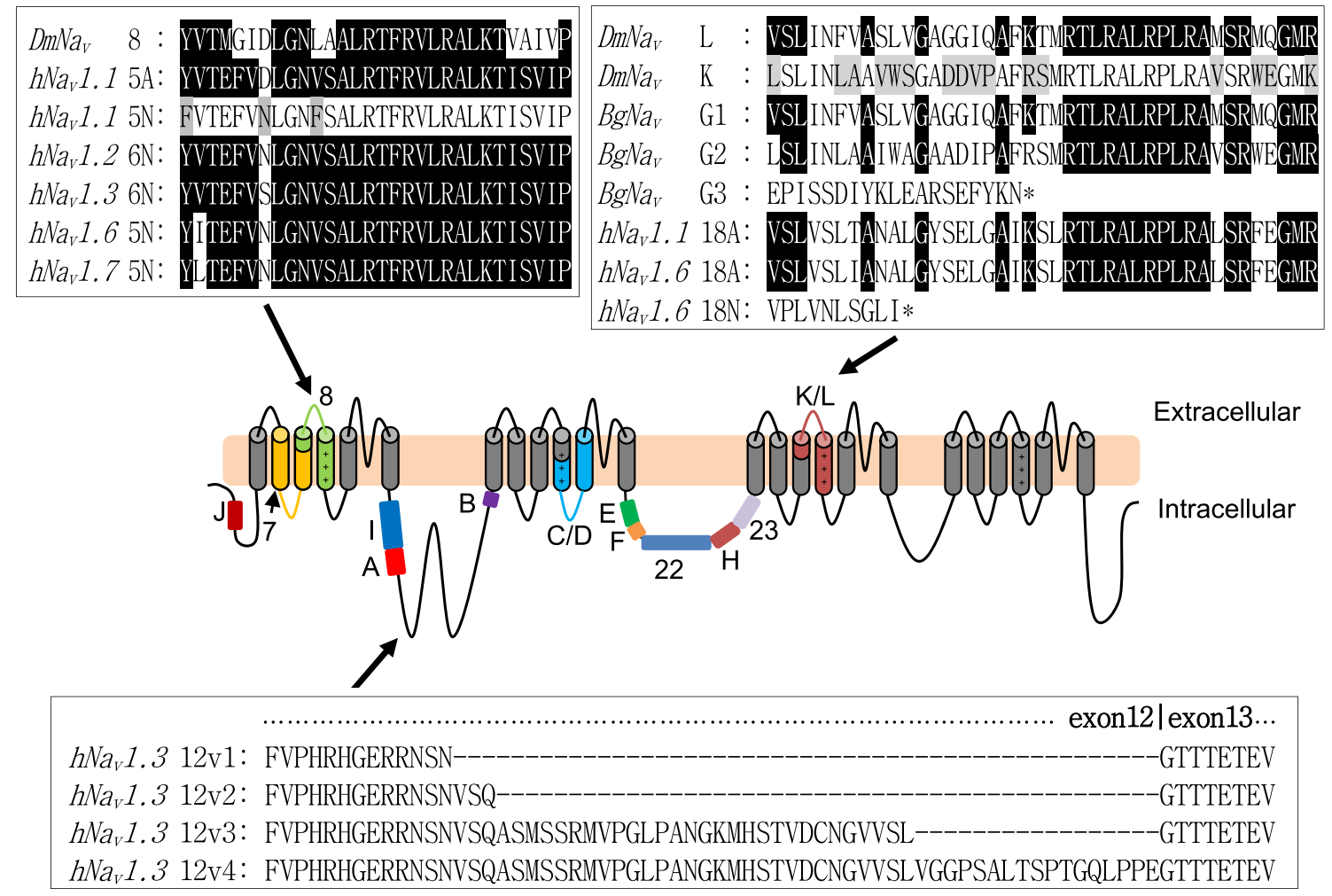

Fig. 1 Schematic of the predicted topology of the voltage-gated sodium channel showing approximate locations of Drosophila spliced exons. Cytoplasmic $D m N a_{v}$ exons $J, 7,8, I, A, B, E, F, 22, H, 23$ are optional, while exons $C / D$ and $K / L$ are mutually exclusive. $D m N a_{v}$ exon 8 is conserved in human $\mathrm{Na}_{\mathrm{v}} \mathrm{s}$ as mutually exclusive spliced exons $5 \mathrm{~A}$ and $5 \mathrm{~N}\left(6 \mathrm{~A}\right.$ and $6 \mathrm{~N}$ in $h N a_{v} 1.2$ and $h N a_{v} 1.3$ due to different exon numbering in the consensus gene sequence), and identical residues are shown in black boxes. Exon $5 \mathrm{~A}$ and $5 \mathrm{~N}$ of $h N a_{v} 1.1$ differ by 3 amino acids, shown in grey boxes in the $5 \mathrm{~N}$ sequence. Mutually exclusive $D m N a_{v}$ spliced exon $\mathrm{L}$ and cockroach $B g N a_{v}$ exon G1 are identical and are conserved in human: exon 18A of $h N a_{v} 1.1$ and $h N a_{v} 1.6 . D m N a_{v}$ exons $\mathrm{K}$ and $\mathrm{L}$ differ by $16 / 41$ residues (shown in grey boxes in the exon $\mathrm{K}$ sequence). Inclusion of $B g N a_{v}$ exon $\mathrm{G} 3$ and $h N a_{v} 1.6$ exon $18 \mathrm{~N}$ generated a truncated channel. Exon 12 of $h N a_{v} 1.3$ is located in the intracellular loop between domains I and II. By using different splice donor sites in exon 12, four spliced variants, $12 \mathrm{v} 1,12 \mathrm{v} 2,12 \mathrm{v} 3$, and $12 \mathrm{v} 4$ can be generated. The amino acid sequences are obtained as follows: $D m N a_{v} 8, \mathrm{~K}$, and L [15]; $h N a_{v} 5 \mathrm{~A}$ and $5 \mathrm{~N}[61] ; h N a_{v} 1.618 \mathrm{~A}$ and $18 \mathrm{~N}$ [23]; $B g N a_{v}$ G1, G2, and G3 [20]; $h N a_{v} 1.312 \mathrm{v} 1,12 \mathrm{v} 2,12 \mathrm{v} 3$, and 12v4 [30]
Table 1 Summary of spliced $N a_{v}$ exons that are known to affect channel kinetics. Predicted influence on neuron excitability due to splicing are stated, increased $(\uparrow)$, decreased $(\downarrow)$, or complex (?)

Specific changes observed to channel kinetics are as follows: depolarising $(\rightarrow)$ or hyperpolarising $(\longleftarrow)$ shifts in activation (act) or inactivation (inact) and/or increased $(\uparrow)$ or decreased $(\downarrow)$ transient $\left(\mathrm{I}_{\mathrm{NaT}}\right)$ or persistent sodium current $\left(\mathrm{I}_{\mathrm{NaP}}\right)$ amplitude

\begin{tabular}{lllll}
\hline Channel & Exon & Expression system & Predicted effect on cell excitability (by changing) & References \\
\hline$D m N a_{v}$ & $J, E$ & Xenopus oocytes & $\downarrow$ (act $\rightarrow)$ & {$[15]$} \\
$D m N a_{v}$ & $F$ & Xenopus oocytes & $\uparrow($ act $\leftarrow)$ & {$[15]$} \\
$D m N a_{v}$ & $H$ & Xenopus oocytes & $\uparrow($ inact $\rightarrow)$ & {$[15]$} \\
$D m N a_{v}$ & $K$ & Xenopus oocytes & $\downarrow\left(\mathrm{I}_{\mathrm{NaP}}\right.$ amplitude $\left.\downarrow\right)$ & {$[15]$} \\
$D m N a_{v}$ & $L$ & Xenopus oocytes & $\uparrow\left(\mathrm{I}_{\mathrm{NaP}}\right.$ amplitude $\left.\uparrow\right)$ & {$[15]$} \\
$h N a_{v} 1.1$ & $5 A$ & HEK293T & $\uparrow\left(\mathrm{I}_{\mathrm{NaP}}\right.$ amplitude $\uparrow$, inact $\left.\rightarrow\right)$ & {$[61]$} \\
$h N a_{v} 1.1$ & $5 N$ & HEK293T & $\downarrow\left(\mathrm{I}_{\mathrm{NaP}}\right.$ amplitude $\downarrow$, inact $\left.\leftarrow\right)$ & {$[61]$} \\
$h N a_{v} 1.3$ & $12 v 1$ & Xenopus oocytes & $\downarrow($ inact $\leftarrow)$ & {$[30]$} \\
$h N a_{v} 1.3$ & $12 v 2$ & Xenopus oocytes & $\downarrow($ act $\rightarrow)$ & {$[30]$} \\
$h N a_{v} 1.3$ & $12 v 3$ & Xenopus oocytes & $\uparrow($ inact $\rightarrow)$ & {$[30]$} \\
$h N a_{v} 1.3$ & $12 v 4$ & Xenopus oocytes & $\uparrow($ act $\leftarrow)$ & {$[28]$} \\
$B g N a_{v}$ & $B$ & Xenopus oocytes & $\uparrow\left(\mathrm{I}_{\mathrm{NaT}}\right.$ amplitude $\left.\uparrow\right)$ & {$[20]$} \\
$B g N a_{v}$ & $G 1$ & Xenopus oocytes & $?\left(\mathrm{I}_{\mathrm{NaT}}\right.$ amplitude $\downarrow$, act $\leftarrow$, inact $\left.\rightarrow\right)$ & {$[20]$} \\
$B g N a_{v}$ & $G 2$ & Xenopus oocytes & $?\left(\mathrm{I}_{\mathrm{NaT}}\right.$ amplitude $\uparrow$, act $\rightarrow$, inact $\left.\leftarrow\right)$ & \\
\hline
\end{tabular}


through phosphorylation in the I-II linker of $\mathrm{Na}_{\mathrm{v}}$ may influence current amplitude without significantly affecting gating properties [11, 32-36].

Persistent Na current and membrane excitability

The persistent Na current $\left(\mathrm{I}_{\mathrm{NaP}}\right)$ has been identified to play critical roles in regulating membrane excitability [37]. Moreover, numerous point mutations in human $N a_{v}$ s, identified in patients with epilepsy, potentiate this component of the voltage-gated $\mathrm{Na}$ current $\left(\mathrm{I}_{\mathrm{Na}}\right)$ [26]. Interestingly, $\mathrm{I}_{\mathrm{NaP}}$ is also a primary target of some clinically used antiepileptic drugs, including phenytoin, valproic acid, and lamotrigine. [38-40]. It is significant, therefore, that the magnitude of this current can be altered through alternative splicing. However, our understanding of the molecular machinery that regulates splicing of $N a_{v} \mathrm{~S}$ is poor. This is unfortunate because a fuller understanding may offer new leads for antiepileptic drug design.

In early behavioural screens of Drosophila, different single-gene mutations were identified that induce a seizurelike phenotype when flies are exposed to strong sensory stimuli. Following a mechanical shock, such as vortexing or harsh-tapping of the culture vial, bang-sensitive (bs) mutant flies exhibit a stereotyped sequence of seizure-like spasms, followed by a period of paralysis, and then a second recovery seizure-like phase that precedes a more complete recovery (Fig. 2) [41, 42]. Despite the evolutionary distance, the resemblance in epileptiform activity between fly and humans and the response to clinical antiepileptic drugs make bs mutants an accepted model for studying epilepsy [42-49]. One such bs mutant—slamdance (sda) - which has a deficiency of aminopeptidase $\mathrm{N}$, exhibits increased seizure-like activity in response to electrical stimulation in the larval stage. Detailed electrophysiology shows that $\mathrm{I}_{\mathrm{NaP}}$ is significantly increased in central motoneurons in this mutant [48]. A molecular analysis reveals that splicing of $D m N a_{v}$ is similarly altered in the $s d a$ mutation to favour inclusion of exon $L$ at the expense of exon $K$ [25]. As previously described (see above), inclusion of exon $L$ results in channels that, when expressed in Xenopus oocytes, exhibit a larger $\mathrm{I}_{\mathrm{NaP}}$ [15]. Seizure-like behaviour, in response to electric shock, along with the increased $\mathrm{I}_{\mathrm{NaP}}$ and increased inclusion of $L$ isoform are all reversed by feeding larvae with antiepileptic drugs (AEDs) including phenytoin (Phy) and gabapentin (Gbp) [25, 48]. Thus, a better understanding of how $\mathrm{I}_{\mathrm{NaP}}$ is regulated, particularly through splicing, may be beneficial for epilepsy therapy.

Activity-dependent alternative splicing regulation of $\mathrm{I}_{\mathrm{NaP}}$ expression

Seizures can be induced in both mammals and flies through ingestion of proconvulsants such as picrotoxin (PTx) [50, 46]. PTx elicits seizure through antagonism of the $\mathrm{GABA}_{\mathrm{A}}$ receptor-suppressing synaptic inhibition [51, 52]. Remarkably, we showed that enhancement of synaptic activity in wild-type larvae, through ingestion of PTx, is sufficient to increase inclusion of exon $L$ in $D m N a_{v}$ increasing $\mathrm{I}_{\mathrm{NaP}}$ as a consequence and inducing a bang-sensitive phenotype. Conversely, seizure activity can be rescued via enhancing synaptic inhibition in $s d a$ through ingestion of GABA [25]. Both manipulations suggest that the 'decision' to splice either exon $L$ or $K$ is dictated by neuronal activity: i.e. activitydependent. Increasing synaptic excitatory input results in greater inclusion of exon $L$, which in turn increases $\mathrm{I}_{\mathrm{NaP}}$ and membrane excitability [25]. Increased excitability would be
Fig. 2 Drosophila bang-sensitive mutant behaviour. Brief vortexing $(\sim 10 \mathrm{~s})$ of the culture vial, containing bang-sensitive mutant flies, induces a stereotyped sequence of seizure-like spasms, followed by a period of paralysis, and then a recovery seizure-like phase that precedes a normal but refractory phase followed ultimately by a complete recovery




predicted to further increase inclusion of exon $L$ up to a maximum of $100 \%$ (which is observed in $s d a$ and other bs mutants). Such a self-reinforcing cycle provides a plausible, although untested, explanation of the clinical observation in which untreated seizures beget seizures, i.e. paroxysmal activity has the potential to promote susceptibility to further seizures [53, 54].

Splicing of $N a_{v}$ transcripts in response to activity provides an important mechanism for inducing changes in excitability. Because of the complexity of the mammalian CNS, with its larger number of expressed $\mathrm{Na}_{\mathrm{v}} \mathrm{s}$, the extent of splicing and its functional consequences are not well understood. However, the high degree of homology between $\mathrm{DmNa}_{\mathrm{v}}$ and its mammalian counterparts allows us to use the former to guide future studies in mammals. Drosophila exon K/L (located in homology domain III S3-4) is conserved in the homologous domain III from insect to mammal [20, 18, 23], although the outcome of splicing differs. Splicing at this location in cockroach produces three mutually exclusive transcripts that contain spliced exons $G 1, G 2$, or G3. G3 contains a stop codon and generates a nonfunctional channel, whereas $\mathrm{G} 1$ and $\mathrm{G} 2$ result in channels that differ in peak $\mathrm{I}_{\mathrm{NaT}}$ amplitude, gating properties (Table 1) and sensitivity to deltamethrin, a pyrethroid insecticide [20]. In mammals, this same region is also spliced in $N a_{v} 1.1$ and $N a_{v} 1.6$ - resulting in the inclusion of exons $18 \mathrm{~A}$ or $18 \mathrm{~N}$ [21-23]. Exon $18 \mathrm{~A}$ predominates in adult brain and $18 \mathrm{~N}$ in embryo and nonneuronal tissues. Similar to the cockroach exon $G 3$, mammalian exon $18 \mathrm{~N}$ contains a stop codon and generates a truncated channel. These truncated $\mathrm{Na}_{\mathrm{v}}$ channels that contain only the first two domains, express mainly in nonneuronal tissues, and are hypothesised to be a 'fail-safe' mechanism to prevent the expression of functional $\mathrm{Na}_{\mathrm{v}} \mathrm{s}$ in nonexcitable cells [55, 23, 21, 22].

A second splicing event in mammalian $\mathrm{Na}_{\mathrm{v}} \mathrm{s}$ is noteworthy because it occurs at the equivalent $\mathrm{S} 3-4$ region of homologous domain I. Similar to $D m N a_{v}$, splicing at exon 5 in $N a_{v} 1.1$ is mutually exclusive with the choice of either exons $5 \mathrm{~A}$ or $5 \mathrm{~N}$ (again for adult and neonatal). Alternative splicing in this region is also observed in $N a_{v} 1.2,1.3,1.6$ and $N a_{v} 1.7$ in both human and mouse [56-60]. In human $\mathrm{Na}_{\mathrm{v}} 1.1$, three amino acids differ between exon $5 \mathrm{~A}$ and $5 \mathrm{~N}$; however, the channels exhibit distinct gating properties. Heterologous expression of human $\mathrm{Na}_{\mathrm{v}} 1.1-5 \mathrm{~N}$, in HEK293T cells, produces channels which exhibit more rapid inactivation and reduced $\mathrm{I}_{\mathrm{NaP}}$ compared to $\mathrm{Na}_{\mathrm{v}} 1.1-5 \mathrm{~A}$. Whilst much needs to be learnt about this splice event, these results suggest that splicing at this location is sufficient to confer changes in neuronal excitability (Table 1) [61]. Intriguingly, inclusion of neonatal exon $6 \mathrm{~N}$ is increased in both $N a_{v} 1.2$ and $N a_{v} 1.3$ following electrical or kainate-induced seizure in adult rat hippocampus [62, 63], perhaps indicative that splicing may similarly be activityregulated in mammals, as it is in the fly.
Pasilla/Nova, critical factors involved in activity-dependent alternative splicing

A screen of RNA-binding proteins in Drosophila first identified Pasilla (Ps) to be sufficient to regulate splicing of mutually exclusive exons $K$ and $L$ in $D m N a_{v}$ [64]. The inclusion of exon $K$ is significantly increased to $50 \%$ in a $p s$ loss-offunction mutant indicating that the presence of Ps is necessary for the inclusion of exon $L$ [15]. Loss of one copy of $p s$ is also sufficient to rescue the bs-associated seizure behaviour of $s d a$ mutants and, moreover, to also prevent PTx-induced seizure in WT background (Fig. 3) [25]. These data suggest that Ps is required for the underlying activity-dependent splicing mechanism. Ps, which contains a K-homology (KH) RNA-binding domain [65, 66], encodes the Drosophila homologue of the human neuro-oncological ventral antigen 1 and 2 (Nova-1 and Nova-2, respectively) proteins $[67,68]$. Nova-1 and Nova-2 are expressed to high levels in brain, however, in largely nonoverlapping patterns [69-71]. By recognising YCAYmotifs, located either in introns or 3'UTRs of target
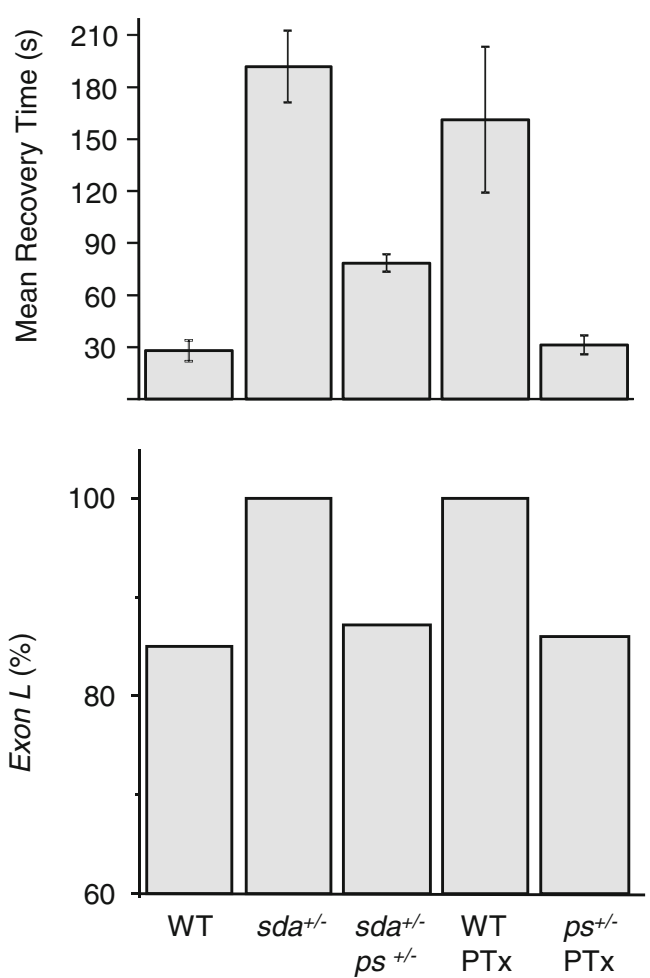

Fig. 3 Pasilla is required for activity-dependent inclusion of exon $L$ of $D m N a_{v}$. Prolonged mean recovery time to electroshock of third instar larvae (i.e. increased severity of seizure) is observed in both slamdance $(s d a)$ mutants and picrotoxin (PTx)-fed WT flies. Analysis of splicing of $D m N a_{v}$ in whole CNS of such larvae shows that inclusion of exon $L$ increased to $\sim 100 \%$. In $s d a$, loss of one copy of pasilla $\left(s d a^{+/-}, p s^{+/-}\right)$is sufficient to decrease the inclusion of exon $L$ and to rescue seizure-like behaviour. Similarly, removal of one copy of $p s$ in WT larvae $\left(p s^{+/-}\right)$ diminishes PTx-induced seizure, as well as inclusion of exon $L$. Data are taken from [25] 
transcripts, Nova1/2 regulate neuronal alternative splicing and also mediate transportation of some target transcripts between the nucleus and cytoplasm [68, 72, 73]. Splicing in at least 17 ion channel genes, including $N a_{v} s$, is predicated to be regulated by Nova-2 [74, 75]. Significantly, overexpression of Nova-2 in HEK293 cells results in an increase in the $N a_{v} 1.1-5 N$ splice variant [75]. In support of this, Nova-2 and $N a_{v} 1.1-5 N$ transcript abundance are upregulated in temporal neocortical tissue of mesial temporal lobe epilepsy patients. [75]. The relationship between Nova expression and epilepsy has been further examined by EEG recordings in Nova $-2^{+/}$heterozygous mice (Nova-2 $2^{-/-}$mice die within 23 weeks of birth). Perturbing Nova steady-state levels in Nova $-2^{+/}$heterozygous mice gives rise to cortical hyperexcitability and also to spontaneous generalised seizure discharge [73]. Moreover, Nova localization shifts from primarily nuclear to cytoplasmic within 2-4 h after pilocarpineinduced seizure [73]. Taken together, these findings strongly implicate perturbation of Nova-2 function contributes to epileptogenesis. The corollary would be that manipulation of Nova activity might be antiepileptic. The conservation of function between Ps and Nova offers the exciting opportunity to utilise Drosophila to rapidly identify molecules that might influence Nova function.

\section{Sodium channel expression and homeostasis}

Control of neuron excitability is known to be achieved at the genomic level through transcriptional regulation of $N a_{v}$ channel genes [1, 3, 76, 6]. In Drosophila CNS, the regulation of the voltage-gated sodium current $\left(\mathrm{I}_{\mathrm{Na}}\right)$ can be achieved through activity-dependent alteration of $D m N a_{v}$ mRNA level $[77,4,5,78]$. Removal of excitatory synaptic inputs to motoneurons, achieved by expressing tetanus toxin light chain in all central neurons, significantly increased $D m N a_{v}$ transcript abundance and also the magnitude of $\mathrm{I}_{\mathrm{Na}}$ in motoneurons. On the other hand, enhanced excitatory synaptic release, achieved by increasing cAMP level in the CNS, decreased both mRNA level and $\mathrm{I}_{\mathrm{Na}}[77,5]$. This homeostatic mechanism is ideally suited to allow membrane excitability to track the degree of synaptic excitation to which a neuron is exposed (i.e. neuronal homeostasis).

Mammalian neurons (e.g. rat) exhibit the same type of activity-dependent homeostasis of membrane excitability [3]. Deprivation of synaptic excitation in cortical neuron cultures, achieved by chronically blocking glutamatergic signalling, resulted in increased $N a_{v} 1.6$ mRNA expression, $\mathrm{I}_{\mathrm{Na}}$, and membrane excitability [79]. The underling mechanism of this homeostatic regulation, in both flies and mammals, requires the protein Pumilio (Pum) [79, 80, 5, 78]. Pumilio is a member of the Pum and FBF (PuF) RNA-binding protein family [81, 82] and is evolutionarily conserved in many species including yeast (Saccharomyces cerevisiae),
C. elegans, Drosophila, Anopheles, zebrafish, Xenopus, mouse, and human [82, 83].

In the fly CNS, activity-dependent increase in Pum level results in the translational repression of $D m N a_{v}$ transcripts, reducing $\mathrm{I}_{\mathrm{Na}}$ and membrane excitability $[5,78]$. This mechanism is dynamic, such that decreasing levels of synaptic excitation results in decreased Pum level, increased $D m N a_{v}$ transcript abundance, and potentiation of membrane excitability. In rat cortical neurons, the level of Pum was similarly observed to be activity-dependent, mirroring the mechanism observed in the fly [79, 84]. Pum is able to repress translation through binding a specific motif - termed Nanos response element (NRE) [85]—present in both $D m N a_{v}$ and rat $N a_{v} 1.6$ transcripts [79, 78]. Once Pum is bound to a transcript, cofactors Nanos [86] and brain tumour [86] are recruited to form a quaternary RNA-protein complex that causes transcript deadenylation [87] and consequently repression of translation. An 8-nucleotide core motif UGUA(A/U/C)AUA [88] of the NRE is sufficient for the binding of Pum to $D m N a_{v}$ transcripts [78], and this motif exists in about $10 \%$ of all Drosophila transcripts [88]. Notably, those $10 \%$ of transcripts were only interrogated for NREs present in the 3'UTR region; however, Pum binds to the NRE located in the 3' end of the open reading frame (ORF) in both $D m N a_{v}$ and rat $N a_{v} 1.6$ [79, 78]. Therefore, there might be many more Pum targets yet to be identified.

In a genome-wide screening of transcripts associated with the RNA-binding region of Pum, more than 1,000 distinct mRNAs were identified [88]. This suggests that Pum is broadly involved in posttranscriptional regulation of many genes. Indeed, in addition to regulating translation of $N a_{v} \mathrm{~S}$, Pum has also been implicated to regulate dendritogenesis [89, 90], expression of glutamate receptors [91], and aspects of memory and learning in higher brain centres [92]. Behaviour training of long-term memory (LTM) produced by spaced training (ten training sessions with a 15-min rest interval between each session), compared to anaesthesia-resistant memory (ARM) produced by massed training (ten training sessions without rest intervals), resulted in pum mRNA upregulation. Pum mutant flies also showed defects in LTM formation. [92]. Pum regulates NMJ morphology via negative regulation of the translational factor eIF-4E expression by directly binding to an NRE in the 3'UTR of the $e I F-4 E$ transcript [90]. Pum loss-of-function mutants show enhanced expression of eIF-4E and upregulated GluRIIA expression and increased frequency of spontaneous neurotransmitter release [91]. Thus, Pum is seemingly central to many aspects of CNS function, not least of which is homeostatic control of neuronal excitability. In this regard, it is significant that in mouse, Pum2 deficiency leads to spontaneous EEG abnormalities and lower seizure thresholds to the proconvulsant pentylenetetrazole [93]. Similar to Pum, the $N a_{v} 1.6$ transcript is upregulated in CELF4 (CUGBP, ELAV-like family 
member 4) deficient mice [94]. CELF4 is similarly a brainspecific neuronal RNA-binding protein and binds to the 3'UTR of $N a_{v}$ 1.6. Because mammalian $\mathrm{Na}_{\mathrm{v}} 1.6$ is the primary determinant of action potential initiation and main contributor of $\mathrm{I}_{\mathrm{NaP}}$ in excitatory neurons, upregulated $N a_{v} 1.6 \mathrm{mRNA}$ results in increasing neuronal excitability [95]. Consequently, CELF4 deficient mice exhibit both convulsive and nonconvulsive (absence-like) seizures and also have a lower seizure threshold $[94,96]$. These findings demonstrate that understanding the regulation of $\mathrm{I}_{\mathrm{Na}}$ or $\mathrm{I}_{\mathrm{NaP}}$ via RNAbinding proteins is a potentially important approach for epilepsy therapy.

\section{Summary and outlook}

Voltage-gated sodium channels are important determinants for controlling membrane excitability. Regulation of $\mathrm{Na}_{\mathrm{v}}$ activity is achieved, at least in part, by coordination of RNA alternative splicing and translational repression of $N a_{v}$ transcripts (Fig. 4). When one considers additional mechanisms of regulation of $\mathrm{Na}_{\mathrm{v}}$ channel activity, including RNA editing [28], phosphorylation [33, 32, 11, 4], trafficking [97, 98], and degradation [98-100], it becomes clear that these channels are subject to both considerable and diverse regulation consistent with the high level of channel diversity observable in the multitude of neuron types in the human brain. The utilisation of model systems, including Drosophila, offers the significant opportunity to rapidly progress understanding in these and related areas.

A particular area where Drosophila is already making a contribution to understanding epilepsy is through modelling human $N a_{v}$ point mutations. A variety of techniques now exist to allow such mutations to be 'knocked-in' to $D m N a_{v}$ Sun et al. [101] recently reported a $N a_{v} 1.1$ (K1270T) knock-in that recapitulates a mutation associated with genetic epilepsy with febrile seizures plus (GEFS+). Electrophysiological analysis shows this to be a gain-of-function mutation that results in a hyperpolarizing shift in the deactivation potential for $\mathrm{I}_{\mathrm{NaP}}$. This approach not only serves to validate the genetic basis of human disease, but also provides a sensitised genetic background for high-throughput, low cost, screens to identify novel compounds that have antiepileptic properties. Identification of novel targets, such as splicing regulators, can also be quickly developed as the basis of screens with the potential advantage of identifying antiepileptic compounds which interact with nontraditional targets. By far the most common targets of currently used AEDs are ion channels and, whilst these offer effective therapeutic targets, there might be much to be gained from identifying additional targets which would facilitate combinatorial therapy. Combinations of AEDs are showing promise for the treatment of intractable epilepsy [102].

Use of Drosophila (and other simple model systems) also offers the prospect of exploring the mechanistic basis of epileptogenesis from understanding how small seizures may lead to larger seizures to providing novel approaches to prevent epilepsy from progressing, even when an epilepsy-associated mutation is present. For example, we recently reported that the presence of phenytoin, during embryogenesis when the CNS first forms neural circuits, prevents the normal seizure phenotype characteristic of the Drosophila sda mutant [48]. The inference from this study is that early intervention may be beneficial in blocking epileptogenesis by preventing activity-dependent feedback mechanisms that we spotlight in this review. The finding of conservation of regulatory mechanisms between insects such as Drosophila and mammals validates the use of simpler model organisms to provide better understanding of $N a_{v}$ regulation in humans with an obvious benefit of novel therapies for epilepsy.

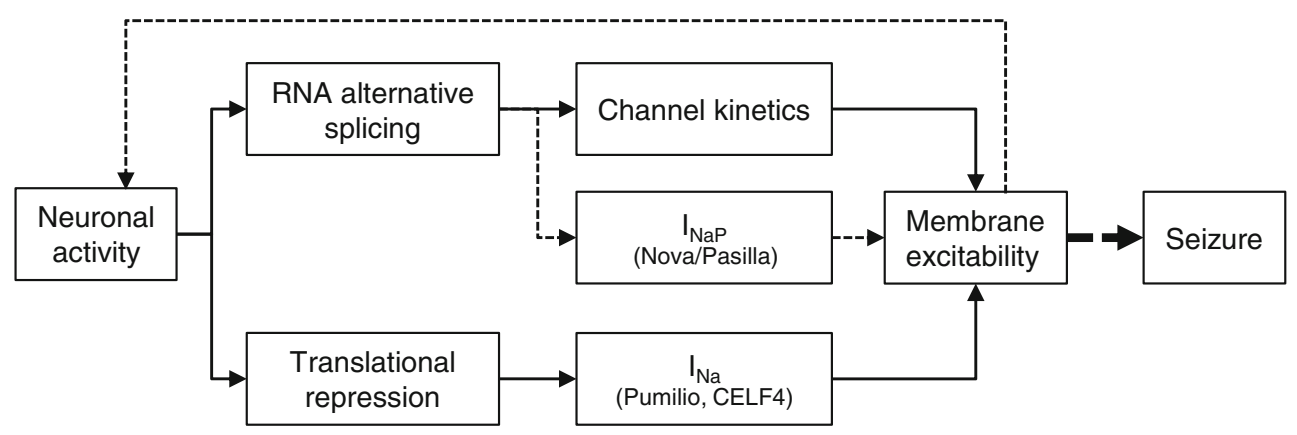

Fig. 4 Membrane excitability is regulated by activity-dependent RNA alternative splicing and translational repression of voltage-gated sodium channel transcripts. Control of membrane excitability through $\mathrm{Na}_{\mathrm{v}}$ activity is achieved by regulation of channel kinetics, current density $\left(\mathrm{I}_{\mathrm{Na}}\right)$, and magnitude of persistent $\mathrm{Na}$ current $\left(\mathrm{I}_{\mathrm{NaP}}\right)$. RNA alternative splicing results in splice variants which exhibit different channel gating properties including activation and inactivation kinetics and $\mathrm{I}_{\mathrm{NaP}}$. Splicing is regulated, in part, by Pasilla in Drosophila and in humans by its homologue, Nova. In Drosophila, increased synaptic excitation results in increased $\mathrm{I}_{\mathrm{NaB}}$, which in turn feeds back to further increase synaptic excitation. This self-reinforcing cycle likely further increases $\mathrm{I}_{\mathrm{NaP}}$ (dashed line) leading to seizure. Current density of $\mathrm{Na}_{\mathrm{v}}$ can be regulated through a mechanism of translational repression of $N a_{v}$ transcripts via Pumilio and possibly CELF4 
Acknowledgments We thank Dr. Stephanie Schorge (UCL, UK) for commenting on the manuscript. We also thank members of the Baines group for helpful comments and advice. Research in the Baines lab is supported by both the BBSRC (BB/J005002/1) and MRC (MR/J009180/1).

Open Access This article is distributed under the terms of the Creative Commons Attribution License which permits any use, distribution, and reproduction in any medium, provided the original author(s) and the source are credited.

\section{References}

1. Turrigiano GG, Nelson SB (1998) Thinking globally, acting locally: AMPA receptor turnover and synaptic strength. Neuron 21(5):933-935

2. Catterall WA (2000) From ionic currents to molecular mechanisms: the structure and function of voltage-gated sodium channels. Neuron 26(1):13-25

3. Desai NS, Rutherford LC, Turrigiano GG (1999) Plasticity in the intrinsic excitability of cortical pyramidal neurons. Nature neuroscience 2(6):515-520. doi:10.1038/9165

4. Baines RA (2003) Postsynaptic protein kinase A reduces neuronal excitability in response to increased synaptic excitation in the Drosophila CNS. The Journal of neuroscience : the official journal of the Society for Neuroscience 23(25):8664-8672

5. Mee CJ, Pym EC, Moffat KG, Baines RA (2004) Regulation of neuronal excitability through pumilio-dependent control of a sodium channel gene. The Journal of neuroscience : the official journal of the Society for Neuroscience 24(40):8695-8703. doi:10.1523/ JNEUROSCI.2282-04.2004

6. Marder E, Goaillard JM (2006) Variability, compensation and homeostasis in neuron and network function. Nature reviews Neuroscience 7(7):563-574. doi:10.1038/nrn1949

7. Schulz DJ, Baines RA, Hempel CM, Li L, Liss B, Misonou H (2006) Cellular excitability and the regulation of functional neuronal identity: from gene expression to neuromodulation. The Journal of neuroscience : the official journal of the Society for Neuroscience 26(41):10362-10367. doi:10.1523/JNEUROSCI.3194-06.2006

8. Goldin AL (2001) Resurgence of sodium channel research. Annual review of physiology 63:871-894. doi:10.1146/annurev.physiol.63.1. 871

9. Li Q, Lee JA, Black DL (2007) Neuronal regulation of alternative pre-mRNA splicing. Nature reviews Neuroscience 8(11):819-831. doi:10.1038/nrn2237

10. Dong K (2007) Insect sodium channels and insecticide resistance. Invertebrate neuroscience : IN 7(1):17-30. doi:10.1007/s10158006-0036-9

11. Smith RD, Goldin AL (1996) Phosphorylation of brain sodium channels in the I-II linker modulates channel function in Xenopus oocytes. The Journal of neuroscience : the official journal of the Society for Neuroscience 16(6):1965-1974

12. Smith RD, Goldin AL (2000) Potentiation of rat brain sodium channel currents by PKA in Xenopus oocytes involves the I-II linker. American journal of physiology Cell physiology 278(4): C638-C645

13. Feng G, Deak P, Chopra M, Hall LM (1995) Cloning and functional analysis of TipE, a novel membrane protein that enhances Drosophila para sodium channel function. Cell 82(6):1001-1011

14. Olson RO, Liu Z, Nomura Y, Song W, Dong K (2008) Molecular and functional characterization of voltage-gated sodium channel variants from Drosophila melanogaster. Insect biochemistry and molecular biology 38(5):604-610. doi:10.1016/j.ibmb.2008.01.003

15. Lin WH, Wright DE, Muraro NI, Baines RA (2009) Alternative splicing in the voltage-gated sodium channel DmNav regulates activation, inactivation, and persistent current. Journal of neurophysiology 102(3):1994-2006. doi:10.1152/jn.00613.2009

16. Pan Q, Shai O, Lee LJ, Frey BJ, Blencowe BJ (2008) Deep surveying of alternative splicing complexity in the human transcriptome by high-throughput sequencing. Nature genetics 40(12):1413-1415. doi:10.1038/ng.259

17. Wang ET, Sandberg R, Luo S, Khrebtukova I, Zhang L, Mayr C, Kingsmore SF, Schroth GP, Burge CB (2008) Alternative isoform regulation in human tissue transcriptomes. Nature 456(7221):470 476. doi: $10.1038 /$ nature 07509

18. Davies TG, Field LM, Usherwood PN, Williamson MS (2007) A comparative study of voltage-gated sodium channels in the Insecta: implications for pyrethroid resistance in Anopheline and other Neopteran species. Insect molecular biology 16(3):361-375. doi: 10.1111/j.1365-2583.2007.00733.x

19. Lee SH, Ingles PJ, Knipple DC, Soderlund DM (2002) Developmental regulation of alternative exon usage in the house fly Vssc1 sodium channel gene. Invertebrate neuroscience : IN 4(3):125-133. doi:10.1007/s10158-001-0014-1

20. Tan J, Liu Z, Nomura Y, Goldin AL, Dong K (2002) Alternative splicing of an insect sodium channel gene generates pharmacologically distinct sodium channels. The Journal of neuroscience : the official journal of the Society for Neuroscience 22(13):5300-5309, doi:20026551

21. Diss JK, Archer SN, Hirano J, Fraser SP, Djamgoz MB (2001) Expression profiles of voltage-gated $\mathrm{Na}(+)$ channel alpha-subunit genes in rat and human prostate cancer cell lines. Prostate 48(3): 165-178. doi:10.1002/pros.1095

22. Oh Y, Waxman SG (1998) Novel splice variants of the voltagesensitive sodium channel alpha subunit. Neuroreport 9(7):1267-1272

23. Plummer NW, McBurney MW, Meisler MH (1997) Alternative splicing of the sodium channel SCN8A predicts a truncated twodomain protein in fetal brain and non-neuronal cells. The Journal of biological chemistry 272(38):24008-24015

24. Kiss T (2008) Persistent Na-channels: origin and function. A review. Acta biologica Hungarica 59(Suppl):1-12. doi:10.1556/ ABiol.59.2008.Suppl.1

25. Lin WH, Gunay C, Marley R, Prinz AA, Baines RA (2012) Activity-dependent alternative splicing increases persistent sodium current and promotes seizure. The Journal of neuroscience : the official journal of the Society for Neuroscience 32(21):7267-7277. doi:10.1523/JNEUROSCI.6042-11.2012

26. Stafstrom CE (2007) Persistent sodium current and its role in epilepsy. Epilepsy currents / American Epilepsy Society 7(1):1522. doi:10.1111/j.1535-7511.2007.00156.x

27. Escayg A, Goldin AL (2010) Sodium channel SCN1A and epilepsy: mutations and mechanisms. Epilepsia 51(9):1650-1658. doi:10. 1111/j.1528-1167.2010.02640.x

28. Song W, Liu Z, Tan J, Nomura Y, Dong K (2004) RNA editing generates tissue-specific sodium channels with distinct gating properties. The Journal of biological chemistry 279(31):32554-32561. doi:10.1074/jbc.M402392200

29. Dietrich PS, McGivern JG, Delgado SG, Koch BD, Eglen RM, Hunter JC, Sangameswaran L (1998) Functional analysis of a voltage-gated sodium channel and its splice variant from rat dorsal root ganglia. Journal of neurochemistry 70(6):2262-2272

30. Thimmapaya R, Neelands T, Niforatos W, Davis-Taber RA, Choi W, Putman CB, Kroeger PE, Packer J, Gopalakrishnan M, Faltynek CR, Surowy CS, Scott VE (2005) Distribution and functional characterization of human Nav1.3 splice variants. The European journal of neuroscience 22(1):1-9. doi:10.1111/j.1460-9568.2005.04155.x

31. Chatelier A, Dahllund L, Eriksson A, Krupp J, Chahine M (2008) Biophysical properties of human Na v1.7 splice variants and their regulation by protein kinase A. Journal of neurophysiology 99(5): 2241-2250. doi:10.1152/jn.01350.2007 
32. Gershon E, Weigl L, Lotan I, Schreibmayer W, Dascal N (1992) Protein kinase A reduces voltage-dependent $\mathrm{Na}+$ current in Xenopus oocytes. The Journal of neuroscience : the official journal of the Society for Neuroscience 12(10):3743-3752

33. Li M, West JW, Lai Y, Scheuer T, Catterall WA (1992) Functional modulation of brain sodium channels by cAMP-dependent phosphorylation. Neuron 8(6):1151-1159

34. Murphy BJ, Rossie S, De Jongh KS, Catterall WA (1993) Identification of the sites of selective phosphorylation and dephosphorylation of the rat brain $\mathrm{Na}+$ channel alpha subunit by cAMPdependent protein kinase and phosphoprotein phosphatases. The Journal of biological chemistry 268(36):27355-27362

35. Smith RD, Goldin AL (1997) Phosphorylation at a single site in the rat brain sodium channel is necessary and sufficient for current reduction by protein kinase A. The Journal of neuroscience : the official journal of the Society for Neuroscience 17(16): 6086-6093

36. Cantrell AR, Smith RD, Goldin AL, Scheuer T, Catterall WA (1997) Dopaminergic modulation of sodium current in hippocampal neurons via cAMP-dependent phosphorylation of specific sites in the sodium channel alpha subunit. The Journal of neuroscience : the official journal of the Society for Neuroscience 17(19):7330-7338

37. Yue C, Remy S, Su H, Beck H, Yaari Y (2005) Proximal persistent $\mathrm{Na}+$ channels drive spike afterdepolarizations and associated bursting in adult CA1 pyramidal cells. The Journal of neuroscience : the official journal of the Society for Neuroscience 25(42):9704-9720. doi:10.1523/JNEUROSCI.1621-05.2005

38. Chao TI, Alzheimer C (1995) Effects of phenytoin on the persistent $\mathrm{Na}+$ current of mammalian CNS neurones. Neuroreport 6(13):17781780

39. Taverna S, Mantegazza M, Franceschetti S, Avanzini G (1998) Valproate selectively reduces the persistent fraction of $\mathrm{Na}+$ current in neocortical neurons. Epilepsy research 32(1-2):304-308

40. Spadoni F, Hainsworth AH, Mercuri NB, Caputi L, Martella G, Lavaroni F, Bernardi G, Stefani A (2002) Lamotrigine derivatives and riluzole inhibit INa, P in cortical neurons. Neuroreport 13(9): $1167-1170$

41. Ganetzky B, Wu CF (1982) Drosophila mutants with opposing effects on nerve excitability: genetic and spatial interactions in repetitive firing. Journal of neurophysiology 47(3):501-514

42. Lee J, Wu CF (2002) Electroconvulsive seizure behavior in Drosophila: analysis of the physiological repertoire underlying a stereotyped action pattern in bang-sensitive mutants. The Journal of neuroscience : the official journal of the Society for Neuroscience 22(24):11065-11079

43. Kuebler D, Tanouye M (2002) Anticonvulsant valproate reduces seizure-susceptibility in mutant Drosophila. Brain research 958(1): 36-42

44. Reynolds ER, Stauffer EA, Feeney L, Rojahn E, Jacobs B, McKeever C (2004) Treatment with the antiepileptic drugs phenytoin and gabapentin ameliorates seizure and paralysis of Drosophila bang-sensitive mutants. Journal of neurobiology 58(4):503-513. doi:10.1002/neu.10297

45. Tan JS, Lin F, Tanouye MA (2004) Potassium bromide, an anticonvulsant, is effective at alleviating seizures in the Drosophila bangsensitive mutant bang senseless. Brain research 1020(1-2):45-52. doi:10.1016/j.brainres.2004.05.111

46. Stilwell GE, Saraswati S, Littleton JT, Chouinard SW (2006) Development of a Drosophila seizure model for in vivo highthroughput drug screening. The European journal of neuroscience 24(8):2211-2222. doi:10.1111/j.1460-9568.2006.05075.x

47. Song J, Tanouye MA (2008) From bench to drug: human seizure modeling using Drosophila. Progress in neurobiology 84(2):182191. doi:10.1016/j.pneurobio.2007.10.006

48. Marley R, Baines RA (2011) Increased persistent $\mathrm{Na}+$ current contributes to seizure in the slamdance bang-sensitive Drosophila mutant. Journal of neurophysiology 106(1):18-29. doi:10.1152/jn. 00808.2010

49. Parker L, Padilla M, Du Y, Dong K, Tanouye MA (2011) Drosophila as a model for epilepsy: bss is a gain-of-function mutation in the para sodium channel gene that leads to seizures. Genetics 187(2):523-534. doi:10.1534/genetics.110.123299

50. White HS (2003) Preclinical development of antiepileptic drugs: past, present, and future directions. Epilepsia 44(Suppl 7):2-8

51. Constanti A (1978) The "mixed" effect of picrotoxin on the GABA dose/conductance relation recorded from lobster muscle. Neuropharmacology 17(3):159-167

52. Jones-Davis DM, Macdonald RL (2003) GABA(A) receptor function and pharmacology in epilepsy and status epilepticus. Current opinion in pharmacology 3(1):12-18

53. Reynolds EH (1987) Early treatment and prognosis of epilepsy. Epilepsia 28(2):97-106

54. Chadwick DW (2008) The treatment of the first seizure: the benefits. Epilepsia 49(Suppl 1):26-28. doi:10.1111/j.1528-1167.2008.01446.x

55. Plummer NW, Galt J, Jones JM, Burgess DL, Sprunger LK, Kohrman DC, Meisler MH (1998) Exon organization, coding sequence, physical mapping, and polymorphic intragenic markers for the human neuronal sodium channel gene SCN8A. Genomics 54(2):287-296. doi:10.1006/geno.1998.5550

56. Sarao R, Gupta SK, Auld VJ, Dunn RJ (1991) Developmentally regulated alternative RNA splicing of rat brain sodium channel mRNAs. Nucleic acids research 19(20):5673-5679

57. Yarowsky PJ, Krueger BK, Olson CE, Clevinger EC, Koos RD (1991) Brain and heart sodium channel subtype mRNA expression in rat cerebral cortex. Proc Natl Acad Sci U S A 88(21): 9453-9457

58. Gustafson TA, Clevinger EC, O’Neill TJ, Yarowsky PJ, Krueger BK (1993) Mutually exclusive exon splicing of type III brain sodium channel alpha subunit RNA generates developmentally regulated isoforms in rat brain. The Journal of biological chemistry 268(25):18648-18653

59. Raymond CK, Castle J, Garrett-Engele P, Armour CD, Kan Z, Tsinoremas N, Johnson JM (2004) Expression of alternatively spliced sodium channel alpha-subunit genes. Unique splicing patterns are observed in dorsal root ganglia. The Journal of biological chemistry 279(44):46234-46241. doi:10.1074/jbc. M406387200

60. Kasai N, Fukushima K, Ueki Y, Prasad S, Nosakowski J, Sugata K, Sugata A, Nishizaki K, Meyer NC, Smith RJ (2001) Genomic structures of SCN2A and SCN3A-candidate genes for deafness at the DFNA16 locus. Gene 264(1):113-122

61. Fletcher EV, Kullmann DM, Schorge S (2011) Alternative splicing modulates inactivation of type 1 voltage-gated sodium channels by toggling an amino acid in the first S3-S4 linker. The Journal of biological chemistry 286(42):36700-36708. doi:10.1074/jbc.M111.250225

62. Aronica E, Yankaya B, Troost D, van Vliet EA, Lopes da Silva FH, Gorter JA (2001) Induction of neonatal sodium channel II and III alpha-isoform mRNAs in neurons and microglia after status epilepticus in the rat hippocampus. The European journal of neuroscience 13(6):1261-1266

63. Gastaldi M, Bartolomei F, Massacrier A, Planells R, RobagliaSchlupp A, Cau P (1997) Increase in mRNAs encoding neonatal II and III sodium channel alpha-isoforms during kainate-induced seizures in adult rat hippocampus. Brain research Molecular brain research 44(2):179-190

64. Park JW, Parisky K, Celotto AM, Reenan RA, Graveley BR (2004) Identification of alternative splicing regulators by RNA interference in Drosophila. Proc Natl Acad Sci U S A 101(45):15974-15979. doi:10.1073/pnas.0407004101

65. Siomi H, Matunis MJ, Michael WM, Dreyfuss G (1993) The premRNA binding $\mathrm{K}$ protein contains a novel evolutionarily conserved motif. Nucleic acids research 21(5):1193-1198 
66. Grishin NV (2001) KH domain: one motif, two folds. Nucleic acids research 29(3):638-643

67. Ule J, Jensen KB, Ruggiu M, Mele A, Ule A, Darnell RB (2003) CLIP identifies Nova-regulated RNA networks in the brain. Science 302(5648):1212-1215. doi:10.1126/science. 1090095

68. Ule J, Stefani G, Mele A, Ruggiu M, Wang X, Taneri B, Gaasterland T, Blencowe BJ, Darnell RB (2006) An RNA map predicting Novadependent splicing regulation. Nature 444(7119):580-586. doi:10. 1038/nature05304

69. Buckanovich RJ, Posner JB, Darnell RB (1993) Nova, the paraneoplastic Ri antigen, is homologous to an RNA-binding protein and is specifically expressed in the developing motor system. Neuron 11(4):657-672

70. Yang YY, Yin GL, Darnell RB (1998) The neuronal RNAbinding protein Nova-2 is implicated as the autoantigen targeted in POMA patients with dementia. Proc Natl Acad Sci U S A 95(22):13254-13259

71. Seshaiah P, Miller B, Myat MM, Andrew DJ (2001) pasilla, the Drosophila homologue of the human Nova-1 and Nova-2 proteins, is required for normal secretion in the salivary gland. Developmental biology 239(2):309-322. doi:10.1006/ dbio.2001.0429

72. Racca C, Gardiol A, Eom T, Ule J, Triller A, Darnell RB (2010) The neuronal splicing factor Nova co-localizes with target RNAs in the dendrite. Frontiers in neural circuits 4:5. doi:10.3389/neuro.04. 005.2010

73. Eom T, Zhang C, Wang H, Lay K, Fak J, Noebels JL, Darnell RB (2013) NOVA-dependent regulation of cryptic NMD exons controls synaptic protein levels after seizure. eLife 2:e0178. doi:10.7554/ eLife.00178

74. Ule J, Ule A, Spencer J, Williams A, Hu JS, Cline M, Wang H, Clark T, Fraser C, Ruggiu M, Zeeberg BR, Kane D, Weinstein JN, Blume J, Darnell RB (2005) Nova regulates brain-specific splicing to shape the synapse. Nature genetics 37(8):844-852. doi:10.1038/ ng1610

75. Heinzen EL, Yoon W, Tate SK, Sen A, Wood NW, Sisodiya SM, Goldstein DB (2007) Nova2 interacts with a cis-acting polymorphism to influence the proportions of drug-responsive splice variants of SCN1A. American journal of human genetics 80(5):876883. doi:10.1086/516650

76. Zhang W, Linden DJ (2003) The other side of the engram: experience-driven changes in neuronal intrinsic excitability. Nature reviews Neuroscience 4(11):885-900. doi:10.1038/nrn1248

77. Baines RA, Uhler JP, Thompson A, Sweeney ST, Bate M (2001) Altered electrical properties in Drosophila neurons developing without synaptic transmission. The Journal of neuroscience : the official journal of the Society for Neuroscience 21(5):1523-1531

78. Muraro NI, Weston AJ, Gerber AP, Luschnig S, Moffat KG, Baines RA (2008) Pumilio binds para mRNA and requires Nanos and Brat to regulate sodium current in Drosophila motoneurons. The Journal of neuroscience : the official journal of the Society for Neuroscience 28(9):2099-2109. doi:10.1523/JNEUROSCI.5092-07.2008

79. Driscoll HE, Muraro NI, He M, Baines RA (2013) Pumilio-2 regulates translation of Nav1.6 to mediate homeostasis of membrane excitability. The Journal of neuroscience : the official journal of the Society for Neuroscience 33(23):9644-9654. doi:10.1523/ JNEUROSCI.0921-13.2013

80. Schweers BA, Walters KJ, Stern M (2002) The Drosophila melanogaster translational repressor pumilio regulates neuronal excitability. Genetics 161(3):1177-1185

81. Zamore PD, Williamson JR, Lehmann R (1997) The Pumilio protein binds RNA through a conserved domain that defines a new class of RNA-binding proteins. Rna 3(12):1421-1433

82. Wickens M, Bernstein DS, Kimble J, Parker R (2002) A PUF family portrait: 3'UTR regulation as a way of life. Trends in genetics : TIG 18(3):150-157
83. Spassov DS, Jurecic R (2003) The PUF family of RNA-binding proteins: does evolutionarily conserved structure equal conserved function? IUBMB life 55(7):359-366. doi:10.1080/ 15216540310001603093

84. Vessey JP, Vaccani A, Xie Y, Dahm R, Karra D, Kiebler MA, Macchi P (2006) Dendritic localization of the translational repressor pumilio 2 and its contribution to dendritic stress granules. The Journal of neuroscience : the official journal of the Society for Neuroscience 26(24):6496-6508. doi:10.1523/JNEUROSCI.064906.2006

85. Murata Y, Wharton RP (1995) Binding of pumilio to maternal hunchback mRNA is required for posterior patterning in Drosophila embryos. Cell 80(5):747-756

86. Sonoda J, Wharton RP (2001) Drosophila brain tumor is a translational repressor. Genes \& development 15(6):762-773. doi:10. 1101/gad.870801

87. Chagnovich D, Lehmann R (2001) Poly(A)-independent regulation of maternal hunchback translation in the Drosophila embryo. Proc Natl Acad Sci U S A 98(20):11359-11364. doi:10.1073/pnas. 201284398

88. Gerber AP, Luschnig S, Krasnow MA, Brown PO, Herschlag D (2006) Genome-wide identification of mRNAs associated with the translational regulator PUMILIO in Drosophila melanogaster. Proc Natl Acad Sci U S A 103(12):4487-4492. doi:10.1073/pnas. 0509260103

89. Ye B, Petritsch C, Clark IE, Gavis ER, Jan LY, Jan YN (2004) Nanos and pumilio are essential for dendrite morphogenesis in Drosophila peripheral neurons. Current biology : CB 14(4):314 321. doi:10.1016/j.cub.2004.01.052

90. Menon KP, Sanyal S, Habara Y, Sanchez R, Wharton RP, Ramaswami M, Zinn K (2004) The translational repressor pumilio regulates presynaptic morphology and controls postsynaptic accumulation of translation factor eIF-4E. Neuron 44(4):663-676. doi: 10.1016/j.neuron.2004.10.028

91. Menon KP, Andrews S, Murthy M, Gavis ER, Zinn K (2009) The translational repressors Nanos and pumilio have divergent effects on presynaptic terminal growth and postsynaptic glutamate receptor subunit composition. The Journal of neuroscience : the official journal of the Society for Neuroscience 29(17):5558-5572. doi: 10.1523/JNEUROSCI.0520-09.2009

92. Dubnau J, Chiang AS, Grady L, Barditch J, Gossweiler S, McNeil J, Smith P, Buldoc F, Scott R, Certa U, Broger C, Tully T (2003) The staufen/pumilio pathway is involved in Drosophila long-term memory. Current biology : CB 13(4):286-296

93. Siemen H, Colas D, Heller HC, Brustle O, Pera RA (2011) Pumilio2 function in the mouse nervous system. PloS one 6(10):e25932. doi:10.1371/journal.pone.0025932

94. Sun W, Wagnon JL, Mahaffey CL, Briese M, Ule J, Frankel WN (2013) Aberrant sodium channel activity in the complex seizure disorder of Celf4 mutant mice. The Journal of physiology 591(Pt 1): 241-255. doi:10.1113/jphysiol.2012.240168

95. Chatelier A, Zhao J, Bois P, Chahine M (2010) Biophysical characterisation of the persistent sodium current of the Nav1.6 neuronal sodium channel: a single-channel analysis. Pflugers Archiv: European journal of physiology 460(1):77-86. doi:10.1007/ s00424-010-0801-9

96. Wagnon JL, Mahaffey CL, Sun W, Yang Y, Chao HT, Frankel WN (2011) Etiology of a genetically complex seizure disorder in Celf4 mutant mice. Genes brain and behavior 10(7):765-777. doi:10. $1111 / j .1601-183 \times .2011 .00717 . \times$

97. Vacher H, Trimmer JS (2012) Trafficking mechanisms underlying neuronal voltage-gated ion channel localization at the axon initial segment. Epilepsia 53(Suppl 9):21-31. doi:10.1111/epi.12032

98. Shao D, Okuse K, Djamgoz MB (2009) Protein-protein interactions involving voltage-gated sodium channels: post-translational regulation, intracellular trafficking and functional expression. The 
international journal of biochemistry \& cell biology 41(7):14711481. doi:10.1016/j.biocel.2009.01.016

99. Ekberg JA, Boase NA, Rychkov G, Manning J, Poronnik P, Kumar S (2014) Nedd4-2 (NEDD4L) controls intracellular $\mathrm{Na}+-$ mediated activity of voltage-gated sodium channels in primary cortical neurons. The Biochemical journal 457(1):27-31. doi:10.1042/BJ20131275

100. Laedermann CJ, Cachemaille M, Kirschmann G, Pertin M, Gosselin RD, Chang I, Albesa M, Towne C, Schneider BL, Kellenberger S, Abriel H, Decosterd I (2013) Dysregulation of voltage-gated sodium channels by ubiquitin ligase NEDD4-2 in neuropathic pain. The Journal of clinical investigation 123(7):3002-3013. doi:10.1172/JCI68996
101. Sun L, Gilligan J, Staber C, Schutte RJ, Nguyen V, O'Dowd DK, Reenan R (2012) A knock-in model of human epilepsy in Drosophila reveals a novel cellular mechanism associated with heat-induced seizure. The Journal of neuroscience : the official journal of the Society for Neuroscience 32(41):14145-14155. doi: 10.1523/JNEUROSCI.2932-12.2012

102. Brigo F, Ausserer H, Tezzon F, Nardone R (2013) When one plus one makes three: the quest for rational antiepileptic polytherapy with supraadditive anticonvulsant efficacy. Epilepsy \& behavior : E\&B 27(3):439-442. doi:10.1016/j. yebeh.2013.03.010 